\title{
Niclosamide suppresses acute myeloid leukemia cell proliferation through inhibition of CREB-dependent signaling pathways
}

\author{
Hee-Don Chae ${ }^{1}$, Nick Cox ${ }^{2}$, Gary V. Dahl' ${ }^{1}$, Norman J. Lacayo ${ }^{1}$, Kara L. Davis ${ }^{1}$, \\ Samanta Capolicchio ${ }^{1,2}$, Mark Smith ${ }^{2}$ and Kathleen M. Sakamoto ${ }^{1}$ \\ ${ }^{1}$ Division of Hematology/Oncology, Department of Pediatrics, Stanford University School of Medicine, Stanford, CA, USA \\ 2 Medicinal Chemistry Knowledge Center, Stanford ChEM-H, Stanford, CA, USA \\ Correspondence to: Kathleen M. Sakamoto, email: kmsakamo@stanford.edu \\ Keywords: niclosamide; acute myeloid leukemia; small molecule; CREB; combination \\ Received: November 03, $2017 \quad$ Accepted: December 22, $2017 \quad$ Published: December 31, 2017
}

Copyright: Chae et al. This is an open-access article distributed under the terms of the Creative Commons Attribution License 3.0 (CC BY 3.0), which permits unrestricted use, distribution, and reproduction in any medium, provided the original author and source are credited.

\section{ABSTRACT}

CREB (CAMP Response Element Binding protein) is a transcription factor that is overexpressed in primary acute myeloid leukemia (AML) cells and associated with a decreased event-free survival and increased risk of relapse. We recently reported a small molecule inhibitor of CREB, XX-650-23, which inhibits CREB activity in AML cells. Structure-activity relationship analysis for chemical compounds with structures similar to XX-650-23 led to the identification of the anthelminthic drug niclosamide as a potent anti-leukemic agent that suppresses cell viability of AML cell lines and primary AML cells without a significant decrease in colony forming activity of normal bone marrow cells. Niclosamide significantly inhibited CREB function and CREBmediated gene expression in cells, leading to apoptosis and G1/S cell cycle arrest with reduced phosphorylated CREB levels. CREB knockdown protected cells from niclosamide treatment-mediated cytotoxic effects. Furthermore, treatment with a combination of niclosamide and CREB inhibitor XX-650-23 showed an additive antiproliferative effect, consistent with the hypothesis that niclosamide and XX-650-23 regulate the same targets or pathways to inhibit proliferation and survival of $A M L$ cells. Niclosamide significantly inhibited the progression of disease in AML patientderived xenograft (PDX) mice, and prolonged survival of PDX mice. Niclosamide also showed synergistic effects with chemotherapy drugs to inhibit AML cell proliferation. While chemotherapy antagonized the cytotoxic potential of niclosamide, pretreatment with niclosamide sensitized cells to chemotherapeutic drugs, cytarabine, daunorubicin, and vincristine. Therefore, our results demonstrate niclosamide as a potential drug to treat AML by inducing apoptosis and cell cycle arrest through inhibition of CREBdependent pathways in AML cells.

\section{INTRODUCTION}

Acute myeloid leukemia (AML) is an aggressive hematologic malignancy that is characterized by the clonal accumulation of immature myeloid progenitors, leading to multilineage cytopenia with a poor outcome [1-4]. As AML results from the accumulation of several oncogenic hits [5], it is a complex disease with genetic and clinical heterogeneity [3]. The cAMP response element binding protein (CREB), a stimulus-induced transcription factor that responds rapidly to phosphorylation and co-activator activation, has been implicated in a number of cancers, including leukemia [6-8]. Upon phosphorylation at Ser133 in its Kinase Inducible Domain (KID) domain, CREB recruits co-activator CREB binding protein (CBP) through interaction between the KID interacting (KIX) domain and the CREB KID domain [9] to induce expression of CREB-driven genes that regulate cell proliferation, signal 
transduction, and cell survival [10-12]. Overexpression of CREB contributes to transformation of hematopoietic cells. CREB is overexpressed at a higher frequency in AML patients and associated with a decreased event-free survival and an increased risk of relapse [6]. Furthermore CREB-overexpression in myeloid cells results in a myeloproliferative disorder in CREB-transgenic mice [13]. CREB knockdown inhibits AML cell proliferation, but does not affect normal hematopoietic stem cell activity in mouse transduction and transplantation experiments [14].

The standard of therapy for AML over the last 40 years has been " $7+3$ " combination chemotherapy, with 7 days of cytarabine plus 3 days of an anthracycline, followed by consolidation chemotherapy or hematopoietic cell transplant [2, 3, 15]. Even with intensive chemotherapy, the overall 5-year survival is less than $60 \%$ in younger patients and less than $10 \%$ in the elderly patients $[2,16]$. Therefore, more effective and less toxic approaches to treat AML are needed. We recently demonstrated the feasibility of targeting CREB for AML treatment using XX-650-23, a small molecule inhibitor of CREB function, which is based on naphthol AS-E phosphate that was first identified as an inhibitor of CREB interaction with its coactivator, CREB Binding Protein (CBP) [17]. Although the CREB inhibitor XX650-23 was more potent than naphthol AS-E phosphate, the small molecule did not have adequate physicochemical properties or sufficient potency for clinical application.

To this end, we performed structure-activity relationship (SAR) studies for chemical compounds with structures similar to XX-650-23. We identified niclosamide, a FDA approved drug with a similar chemical structure that uncouples oxidative phosphorylation in the mitochondria. Niclosamide is an oral anthelminthic drug that has been used worldwide to treat tapeworm infections for 50 years [18-20]. Niclosamide is not toxic in mammals (oral LD50 in rats: over $5000 \mathrm{mg} / \mathrm{kg}$ ) [21] and is well tolerated in humans [22]. Recent studies have proposed that niclosamide has anticancer activity in different cancer types by targeting multiple signaling pathways including NF-kB, Wnt/ $\beta$-catenin, mTORC1, STAT3, and Notch [20, 23-25].

In this study, we demonstrate that niclosamide inhibits CREB-driven gene expression by preventing CREB activation, thereby disrupting CREB-CBP interaction leading to induction of apoptosis and cell cycle arrest in AML cells. We also investigate the in vivo efficacy of niclosamide in AML patient-derived xenograft (PDX) mouse models. Furthermore, combination of niclosamide with chemotherapy showed synergistic effects on AML cells, suggesting that sequential combination of niclosamide with lower doses of " $7+3$ " chemotherapy may provide a more efficacious and less toxic approach to treat AML.

\section{RESULTS}

\section{Niclosamide suppresses AML proliferation as an inhibitor of CREB-dependent pathway}

XX-650-23 was previously shown to inhibit CREB activity and suppress AML cells proliferation in vitro with an $\mathrm{IC}_{50}$ of 1-2 $\mu \mathrm{M}$ and a short half-life when injected intraperitoneally in mice. With the goal of identifying a more potent CREB inhibitor with improved pharmacokinetic properties, we synthesized and tested a series of structural analogs to further develop SAR. At the same time, we searched for existing drugs with known pharmacokinetic and safety profiles using 2D chemical similarity analysis methods [26-28]. This effort led to the identification of the FDA-approved anthelmintic niclosamide as a potential inhibitor of CREB-dependent pathways. Niclosamide shares a number of structural features with XX-650-23 (Figure 1A), including the key salicylanilide core, an electron withdrawing group para to the phenol hydroxyl group, and an electron-withdrawing group para to the anilide. Niclosamide has been reported to exert anti-tumor activity in several cancers including AML [20, 23-25]. We examined the effects of niclosamide on cellular viability of AML cell lines and primary human AML cells. Niclosamide significantly inhibited cellular viability in a dose-dependent manner with $\mathrm{IC}_{50}$ of 0.28 to $0.51 \mu \mathrm{M}$ (Figure 1B). We then investigated the cytotoxic effects of niclosamide in normal bone marrow cells. Though the size of colonies became smaller when treated with over $3 \mu \mathrm{M}$ of niclosamide, colony formation of normal bone marrow cells was not significantly inhibited up to $10 \mathrm{M}$ of niclosamide (18- to 36-fold therapeutic window, Figure 1C). Colony-forming unit-erythroid (CFU-E) was shown to be more vulnerable to niclosamide due to its smaller colony size.

Next, we evaluated whether niclosamide could inhibit CREB activation and subsequent interaction of CREB with CBP. CREB-CBP interaction is dependent on CREB phosphorylation at serine 133. Using the Renilla luciferase complementation assay, we determined niclosamide to be more potent than XX-650-23 as an inhibitor of the CBP KIX-CREB KID domain interaction in a dose dependent manner $\left(\mathrm{IC}_{50}: 1.6 \mu \mathrm{M} v s .3 .8 \mu \mathrm{M}\right)$ (Figure 2A). We next investigated whether CREB inhibition could block CREB-dependent transcription using a CREB-driven luciferase reporter assay in HL60 cells. We used a reporter gene construct expressing luciferase under the control of a promoter containing two cyclic AMP response elements (CRE). Luciferase activity was measured after treatment of HL60 cells with niclosamide for 6 hours. Consistent with the inhibition of KIX-KID interaction, niclosamide reduced CREBdriven luciferase activity in a dose-dependent manner 
A<smiles>N#Cc1ccc(NC(=O)c2cc3ccccc3cc2O)cc1</smiles>

$X X-650-23$<smiles>O=C(Nc1ccc([N+](=O)[O-])cc1Cl)c1cc(Cl)ccc1O</smiles>

\section{Niclosamide}

B

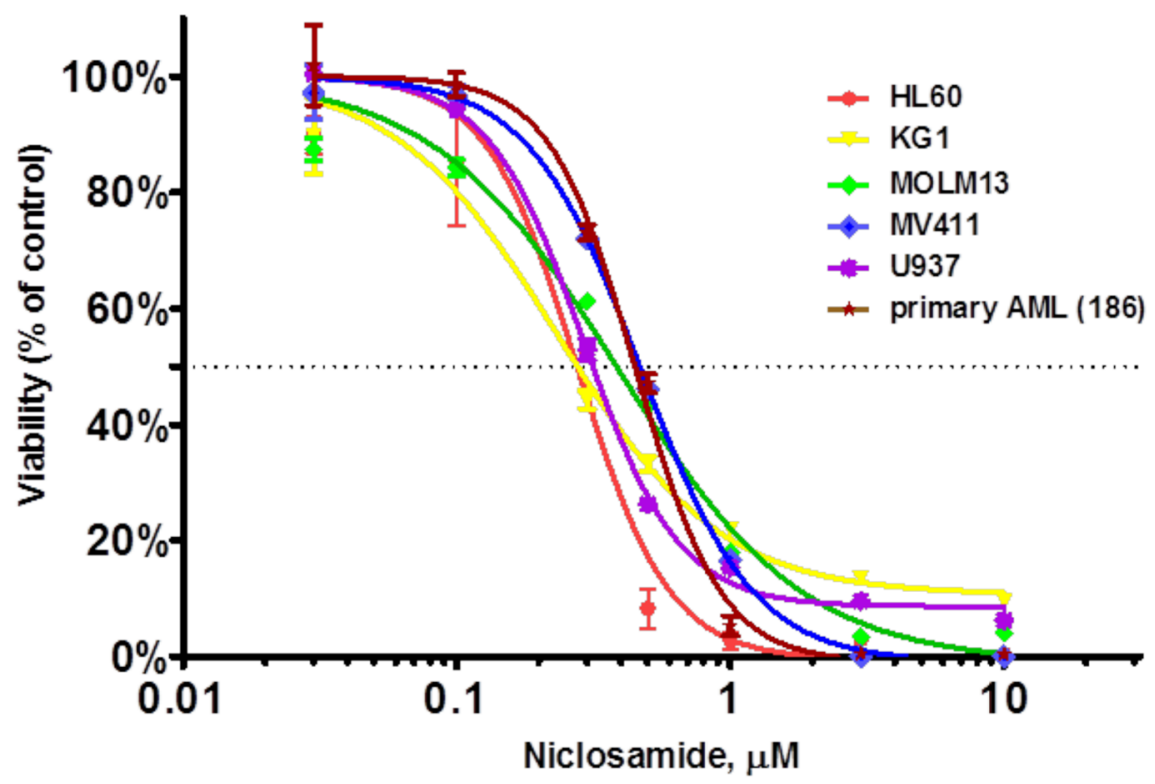

\begin{tabular}{|c|c|c|c|c|c|c|}
\hline & HL60 & KG1 & MOLM13 & MV411 & U937 & 186 \\
\hline $\mathrm{IC}_{50}(\mu \mathrm{M})$ & $0.28 \pm 0.03$ & $0.33 \pm 0.02$ & $0.42 \pm 0.04$ & $0.56 \pm 0.07$ & $0.34 \pm 0.07$ & $0.51 \pm 0.05$ \\
\hline
\end{tabular}

C

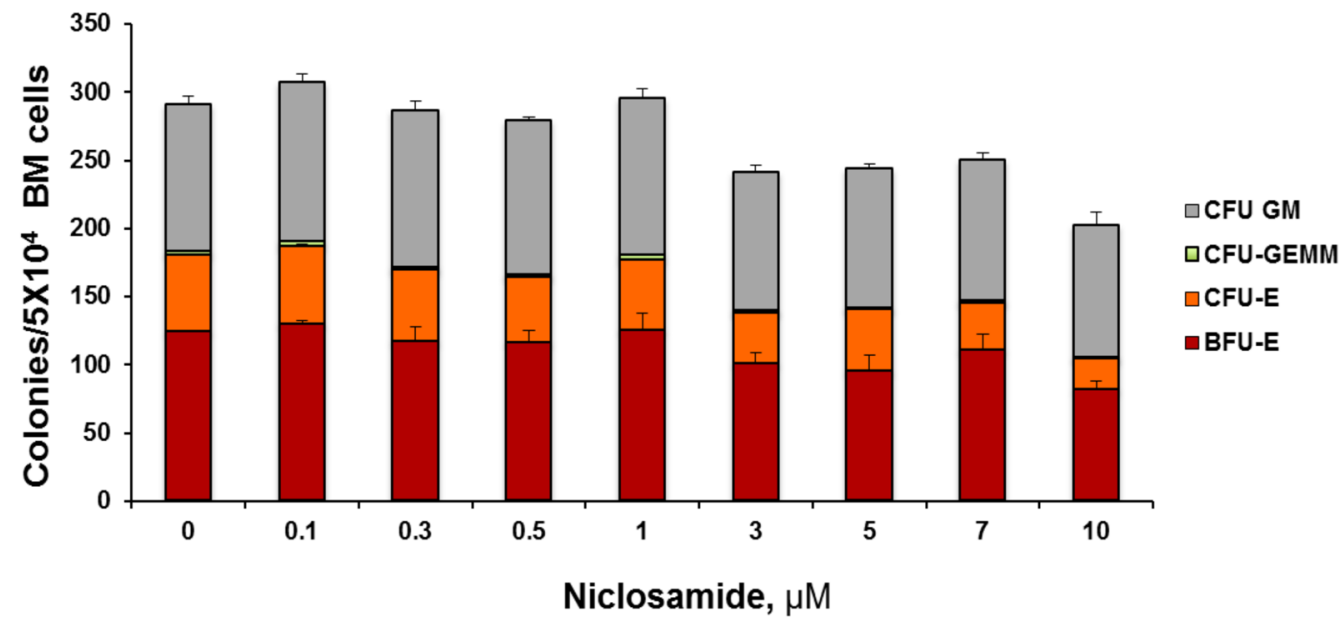

Figure 1: Niclosamide effectively and selectively inhibits viability of AML cells. A. Chemical structure of XX-650-23 and niclosamide. B. AML cells are sensitive to niclosamide. Human AML cell lines and primary AML cells were plated at 2X10 cells/well in 96-well plates, and cultured with niclosamide or vehicle for $3 \mathrm{~d}$ or $4 \mathrm{~d}$, respectively. Cell Titer Glo assay was performed to assess viability of cells. The graphs show representative dose response curves. The $\mathrm{IC}_{50} \mathrm{~s}$ are described below the graph (HL60: $n=54$, KG1: $n=34$, MOLM13: $n=3$, MV411: $n=3$, U937: $n=10,186: n=3)$. C. Effect of niclosamide on normal BM colony forming activity. Normal human bone marrow cells from healthy donors were seeded $\left(3 \times 10^{4}\right.$ cells/plate) in methylcellulose media with niclosamide, and cultured for 2 weeks. Colonies were scored based on morphology. Data are graphed as mean \pm standard error measurement $(\mathrm{SEM})(n=3)$. 
with an $\mathrm{IC}_{50}$ of $1.24 \pm 0.23 \mu \mathrm{M}$ (Figure $2 \mathrm{~B}$ ). To examine the functional requirement of CREB, we determined the effects of CREB knockdown in HL60 cells treated with niclosamide. Knockdown of the cytotoxic drug target could mimic cellular inhibitory phenotype of the drug, and conferred resistance to cytotoxic drug activity [29, 30]. While CREB knockdown itself suppressed the viability of cells to approximately $50 \%$, niclosamide, up to $0.3 \mu \mathrm{M}$, did not further decrease viability of CREB knockdown cells suggesting that $\mathrm{CREB}$ is required for maximal activity of niclosamide in HL60 cells (Figure 2C). CREB knockdown significantly shifted the dose response curve to the right $\left(\mathrm{IC}_{50}=670 \mathrm{nM}\right.$ for CREB knockdown compared to $200 \mathrm{nM}$ for vector control cells), suggesting that CREB is among the targets in cytotoxic response to niclosamide (Figure 2D).

Drug combinations regulating the same target or different targets in the same pathway have been reported to result in additive effects [31]. Thus, we assessed the effects of niclosamide and the CREB inhibitor XX-65023. If additive, the range of combination index (CI) scores should be determined from sham mixtures of the same compound (niclosamide or XX-650-23) [32]. Though $\mathrm{CI}$ values were less than 1 at $\mathrm{ED}_{50}$, they were still in the range of sham mixtures, demonstrating that combination of niclosamide and XX-650-23 was additive in AML cells (Figure 2E). These data suggest that niclosamide is exerting its anti-leukemic effects by inhibiting CREB function similar to XX-650-23.

\section{Niclosamide induces apoptosis and G1/S arrest with suppressed CREB activation}

To identify the mechanism of niclosamide-induced cytotoxicity, we performed apoptosis and cell cycle analysis of niclosamide-treated cells by Annexin-V/ DAPI double staining. Induction of apoptosis at early (Annexin- $\left.\mathrm{V}^{+} / \mathrm{DAPI}\right)$ and late $\left(\right.$ Annexin- $\left.\mathrm{V}^{+} / \mathrm{DAPI}^{+}\right)$stages was clearly observed after 1 day treatment of niclosamide in HL60 and KG1 cells (Figure 3). While most apoptotic cells were at early stage in KG1 cells, HL60 cells showed higher portion of late apoptosis. Since PARP (poly(ADP-ribose) polymerase) is cleaved by caspase-3 during apoptosis [33], cleaved PARP (cPARP) level was determined by flow cytometry to assess caspasedependent apoptosis. Percentage of cPARP-positive cells was distinctly increased $1 \mathrm{~d}$ after niclosamide treatment in both cells (Figure 4A). NF- $\mathrm{BB}$ signaling has been reported as a target molecule of niclosamide in several cancer cells $[23,25]$. To determine the role of CREB and NF- $\kappa B$ in response to niclosamide, we assessed levels of activated phosphorylated CREB [p-CREB(S133)] and NF-кB p65 [p-NF- $\kappa$ B p65 (S536)] in HL60 and KG1 cells by flow cytometry. Niclosamide treatment significantly increased percentage of p-CREB (133)-negative cells, but not p-NFкB p65 (S539)-negative cells (Figure 4B).
As niclosamide has been known to be a STAT3 inhibitor [23, 34], we measured the phosphorylated protein levels of STAT1 (Y701), STAT3 (Y705), and STAT5 (Y694) by flow cytometry. While the percentage of tyrosine-phosphorylated STAT3 (Y705) -negative population was decreased by $8.5 \%$ in KG1 cells, tyrosinephosphorylated STAT1 (701) and STAT5 (Y694) expressed cell populations were increased following niclosamide treatment in KG1 cells. However, we did not observe any differences in the levels of phosphorylated STAT1 (pY705), STAT3 (pY694), and STAT5 (pY701) protein by niclosamide treatment in HL60 cells (Figure 4C). These results suggest that inhibition of STAT3 is not a direct mechanism of niclosamide effect.

We next examined the effects of niclosamide on the cell cycle progression. Niclosamide markedly increased cell population at G1 phase $(60 \%$ in control vs. $75 \%$ in niclosamide treated cells), but decreased the percentage of cells at $\mathrm{S}$ and $\mathrm{G} 2 / \mathrm{M}$ phases (control vs. niclosamidetreated cells, S: $23.90 \pm 0.17$ vs. $10.27 \pm 0.26$; G2/M: $15.04 \pm 0.12$ vs. $12.64 \pm 0.09$, mean $\pm \operatorname{SEM}(n=3), p<$ $.001)$ in cPARP-negative live cell population, indicating that niclosamide inhibits AML cell viability by inducing cell cycle arrest at G1 phase as well as apoptosis (Figure 5A).

To study the effects of niclosamide on CREBtarget genes, we examined the expression of RFC3 and $P O L D 2$, which are factors involved in DNA replication and repair [35]. CREB regulates $\mathrm{G} 1 / \mathrm{S}$ cell cycle transition by controlling $R F C 3$ expression [36]. In addition, mRNA levels of $R F C 3$ and POLD2 are downregulated by CREB knockdown and treatment with CREB inhibitors in AML cells $[17,36,37]$. Quantitative RT-PCR data showed that niclosamide significantly decreased mRNA expression levels of RFC3 and POLD2 in HL60 cells (Figure 5B), suggesting that niclosamide downregulates CREB-target genes to induce apoptosis and cell cycle arrest in AML cells.

\section{In vivo efficacy of niclosamide in AML-PDX mice}

To study the efficacy of niclosamide in AML patient-derived xenograft (PDX) mouse models, we generated PDX models by injecting AML cells from patients into immune-deficient mice [38]. NOD.CgPrkdc scid $I l 2 \mathrm{rg}^{\mathrm{tm} l \mathrm{Wj} l} / \mathrm{SzJ}$ (NSG) mice were transplanted with one million primary AML (186) cells. Mice were treated with niclosamide or vehicle control once daily by oral gavage starting the day after cells were injected. Leukemia disease progression was monitored by measuring the fraction of human $\mathrm{CD} 45^{+}$cells in the peripheral blood (PB) of AML-PDX (186) mice using flow cytometry. Niclosamide significantly inhibited the progression of AML in AML-PDX (186) mice. While vehicle-treated mice showed a rapid increase of circulating leukemia cells in $\mathrm{PB}$, niclosamide treatment suppressed the percentage 
A

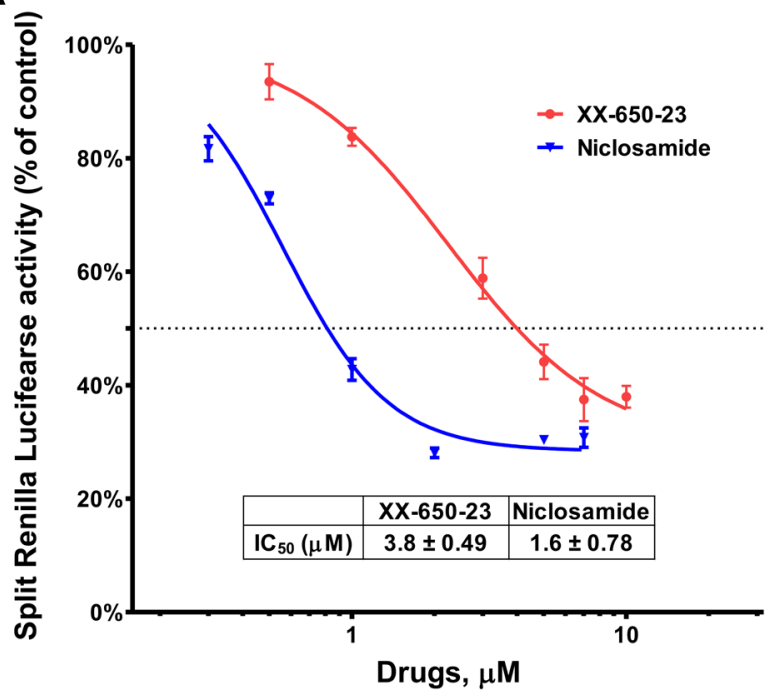

C

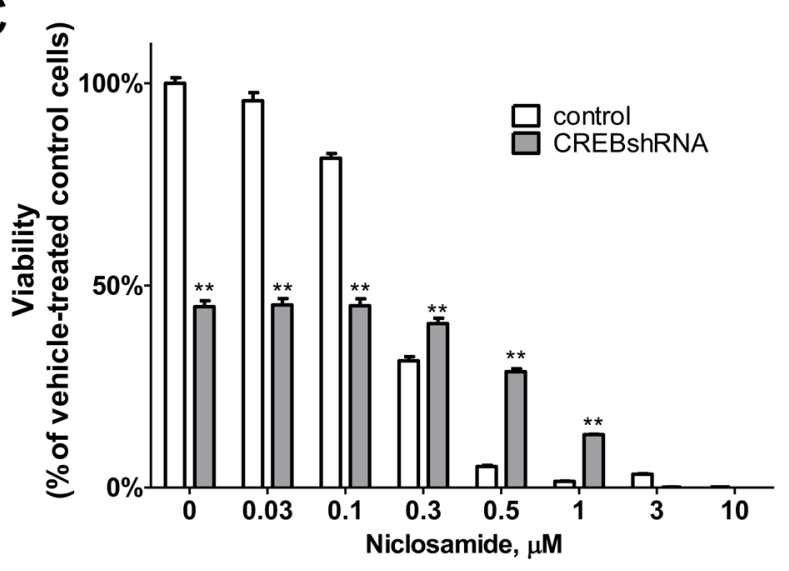

B
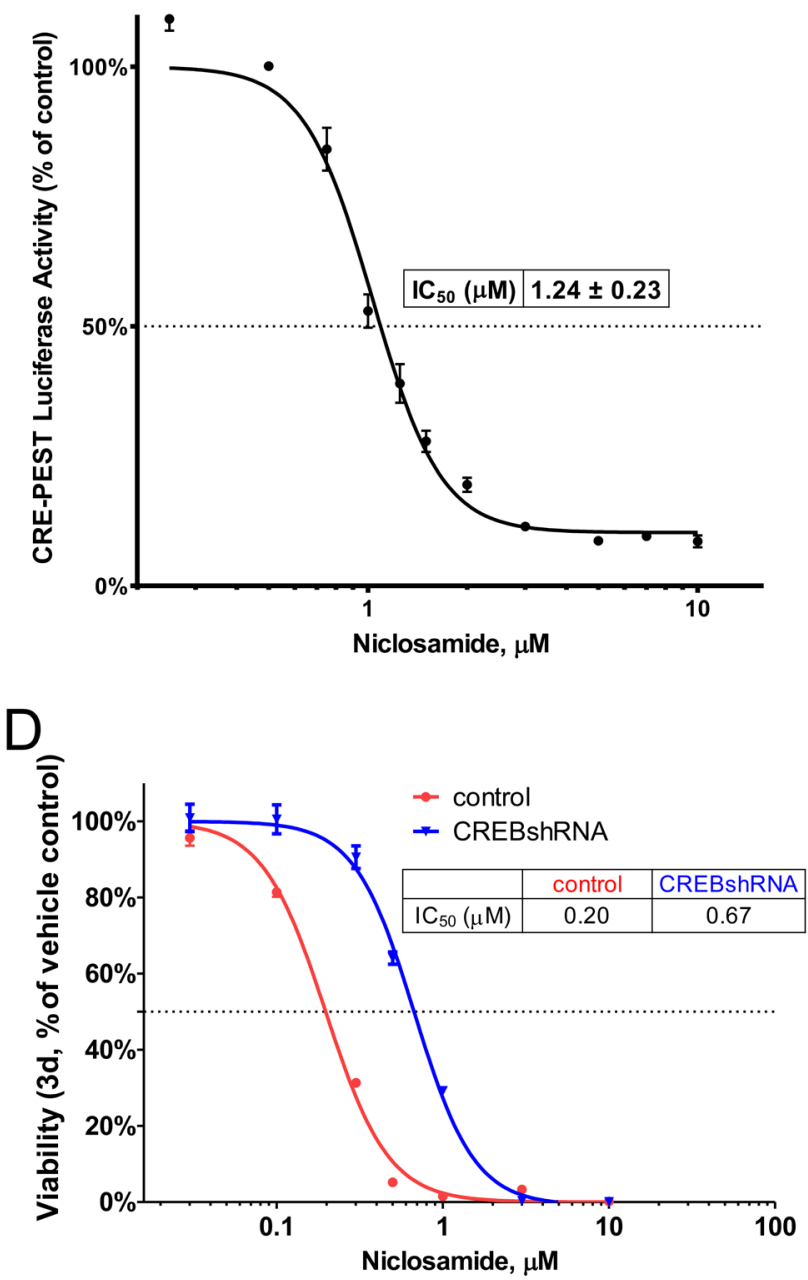

E Additive effective of combination treatment with Niclosamide and XX-650-23

\begin{tabular}{ccccc}
\hline \multicolumn{3}{c}{ HL60 } & \multicolumn{3}{c}{ KG1 } \\
Combination & $\begin{array}{c}\text { Cl Values at } \\
\text { ED50 }\end{array}$ & ED75 & ED50 & ED75 \\
\hline Nic/XX & $0.886 \pm 0.056$ & $1.01 \pm 0.061$ & $0.797 \pm 0.147$ & $1.143 \pm 0.153$ \\
\hline Sham & $0.87-0.92$ & $0.85-0.93$ & $0.64-0.82$ & $1.19-1.23$ \\
\hline
\end{tabular}

Figure 2: Niclosamide inhibits CREB-dependent pathways. A. Niclosamide was more potent than XX-650-23 to inhibit CBP KIX-CREB KID domain interaction. RLucC-KIX and KID-RLucN expressing vectors were transfected into 293 cells. Transfected 293 cells were treated with compounds 30 minutes before forskoin $(6 \mu \mathrm{M})$ stimulation. Cells were further incubated for 90 minutes, and measured Renilla luciferase activity using coelenterazine afterwards. Data are presented as mean \pm SEM $(n=3)$. B. HL60 cells expressing CREB-driven luciferase were generated. Cells were treated with niclosamide for $6 \mathrm{~h}$. Luciferase activity was significantly inhibited by niclosamide treatment. Data are presented as mean $\pm \mathrm{SEM}(n=3)$. The $\mathrm{IC}_{50} \mathrm{~s}$ are described in the graphs. C. CREB knockdown AML cells were more resistant to niclosamide. HL60 cells were transduced with CREB or control shRNA lentivirus. Transduced cells were treated with niclosamide for 3 days. Cell Titer Glo assays were performed. The graph shows that CREB knockdown itself inhibited cellular viability of HL60 cells. Values are indicated as mean $\pm \operatorname{SEM}(n=3) .{ }^{* *}, p<.01$. D. Viability dose-response curve for CREB shRNA transduced cells shifted to the right, suggesting more resistant cells. E. Additive effect of combination treatment with niclosamide and XX-650-23 in HL60 and KG1 cells. Cells were treated with various concentrations of niclosamide (Nic) and XX-650-23 (XX) for 3d. Viability was accessed using CellTiter-Glo assay kit. Combination index (CI) values were calculated by Chou-Talalay method using CalcuSyn software. Data are the mean $\pm \operatorname{SEM}(n=4)$. Additivity ranges of CI scores were determined from sham mixtures of the same compound (niclosamide or XX650-23) in each cell line. 

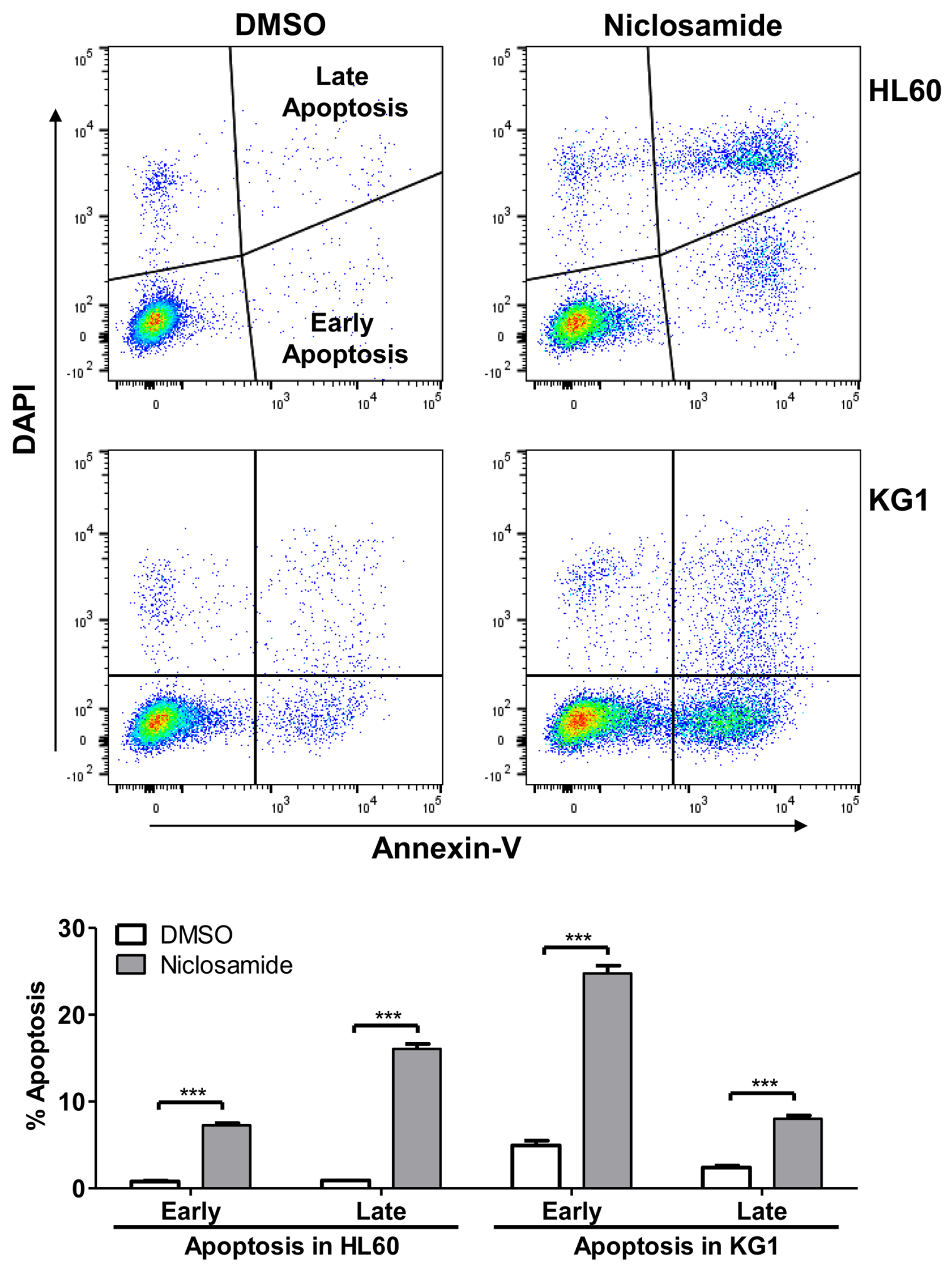

Figure 3: Niclosamide induces apoptosis in AML cells. HL60 (top panels) and KG1 (bottom panels) cells were treated with niclosamide $(1 \mu \mathrm{M}, 24 \mathrm{~h})$. Apoptotic cells were assessed by Annexin-V/DAPI staining. Early apoptotic $\left(\right.$ Annexin- $\left.\mathrm{V}^{+} / \mathrm{DAPI} \mathrm{I}^{-}\right)$and late apoptotic (Annexin- $\mathrm{V}^{+} / \mathrm{DAPI}^{+}$) populations were significantly increased following treatment with niclosamide. Plots are representative of three independent experiments. Percentages of early and late apoptotic cells are graphed as mean $\pm \operatorname{SEM}(n=3) . * * *, p<.0001$. 
A

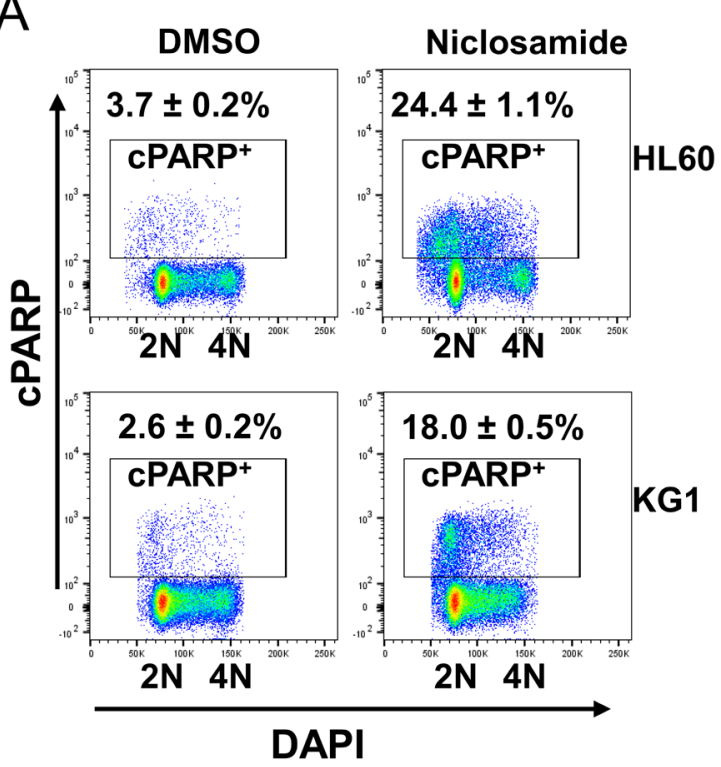

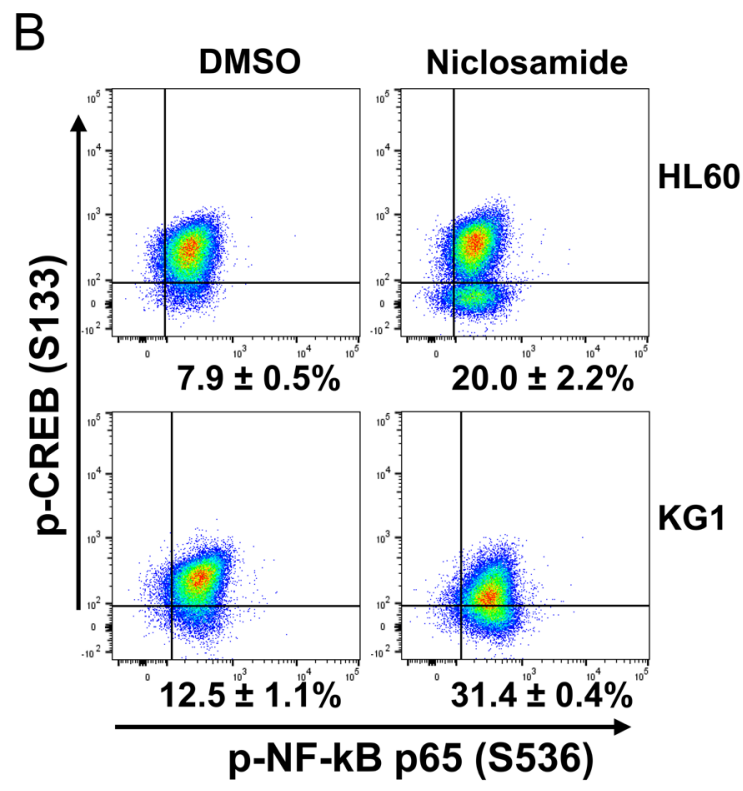

C
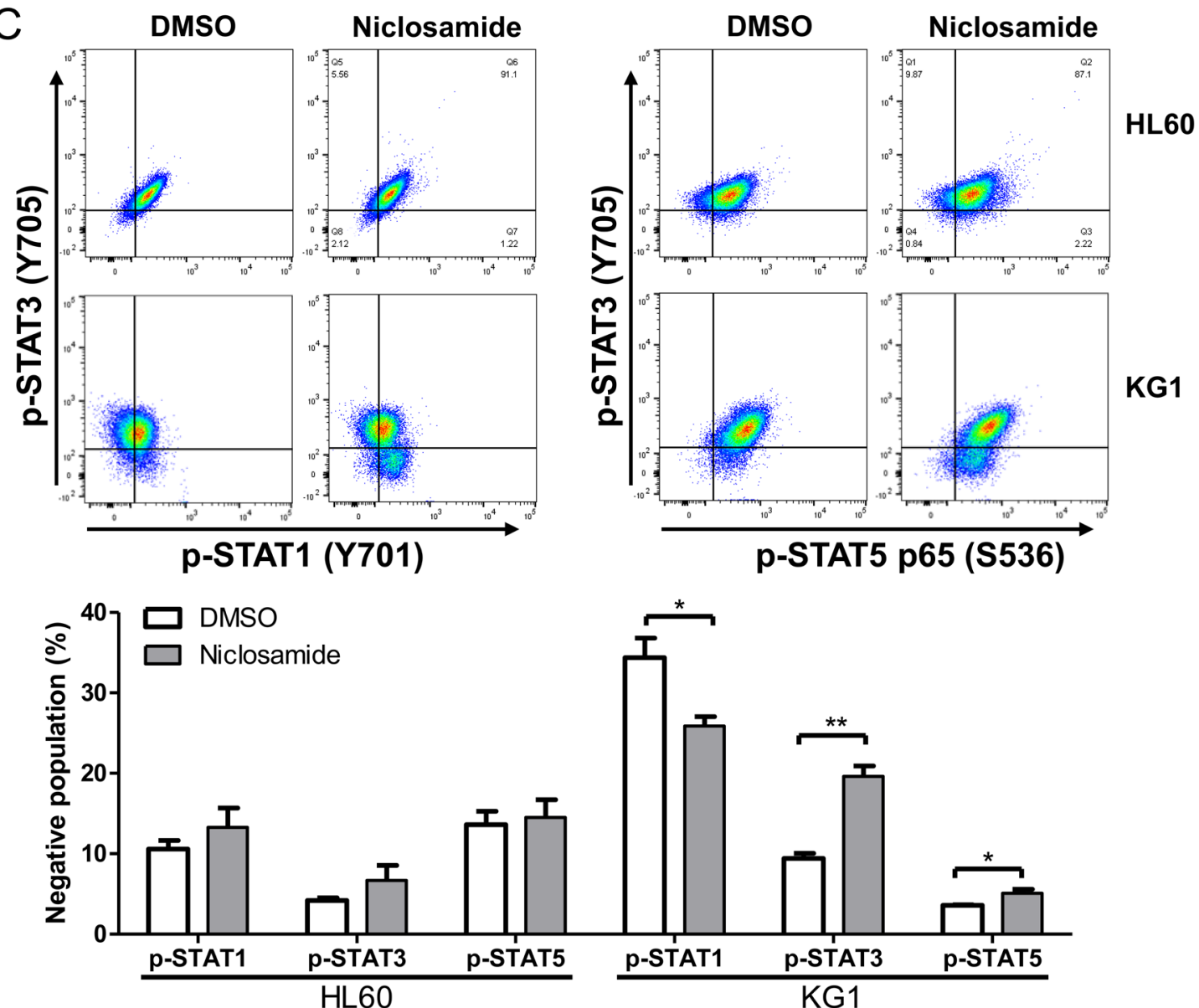

L60

G1

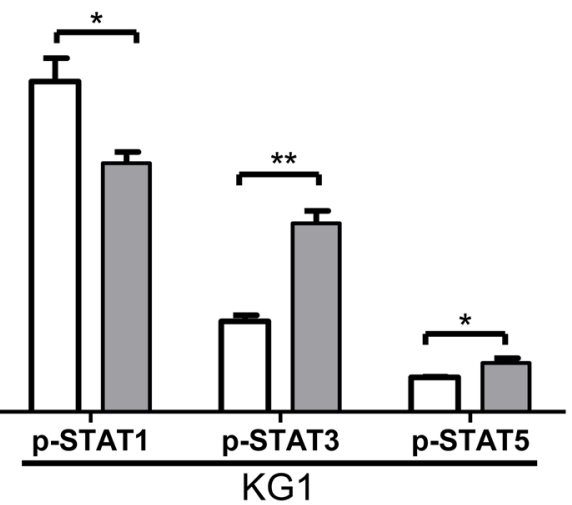

Figure 4: Niclosamide treatment induces apoptosis and suppresses CREB activation. HL60 and KG1cells were treated with $1 \mu \mathrm{M}$ niclosamide for 1d. A. Cells were fixed, and then stained with anti-cleaved PARP (cPARP) antibody and DAPI. Percentages of apoptotic cells are indicated. B. Fixed cells were stained with anti-phospho-CREB(p-CREB) (S133) and anti-phospho-NFkB p65 (S536) antibodies. Plots show the suppression of p-CREB in cells treated with niclosamide as compared with untreated control, but not phosphoNFkB p65. Percentages of p-CREB-negative population are presented as mean $\pm \operatorname{SEM}(n=3)$. C. Cells were stained with anti-phosphoSTAT1 (Y701), anti-phospho-STAT3 (Y705), and anti-phospho-STAT5 (Y694) antibodies. HL60 cells: Top panels, KG1 cells: Bottom panels. Negative populations of each antibody were calculated. Values are graphed as mean $\pm \operatorname{SEM}(n=3) . *, p<.05 ; * *, p<.001$. 
of circulating AML cells to less than $1 \%$ until 5 weeks after transplantation $\left[\mathrm{hCD} 45^{+}\right.$cells in $\mathrm{PB}(\%)$, vehicle $v s$. niclosamide treatment 5 weeks after engraftment, $28.75 \pm 3.51$ vs. $0.54 \pm 0.27(n=8, p<0.001$, mean \pm SEM)] (Figure 6A). Consistent with this inhibitory effect on development of leukemia, niclosamide significantly improved the survival of mice. In Kaplan Meier analysis, the median survival of PDX mice was 41 days $v s .51 .5$ days ( $p=0.0015$, log-rank test) (Figure 6B).

We evaluated the in vivo efficacy of niclosamide with a second AML patient sample (3123). Since AML-PDX (3123) showed a rapid disease onset and a longer median survival, we started treatment 4 weeks after transplantation of leukemia when most mice had an increased leukemic burden of over $20 \%$ for a more clinically relevant experimental model. In this model, niclosamide significantly reduced the leukemic burden more than vehicle control after $1 \mathrm{w}$ of treatment temporarily $\left[\mathrm{hCD} 45^{+}\right.$cells in $\mathrm{PB}(\%)$, vehicle $v s$. niclosamide, $71.92 \pm 2.56$ vs. $61.18 \pm 2.50(n=5, p<$ 0.05 , mean $\pm \mathrm{SEM})]$ (Figure 6C). The median survival of mice was improved compared to vehicle (vehicle: 67 days vs. niclosamide: 72 days), but could not reach statistical significance. Surprisingly, CD $34^{+}$CD 38- leukemic stem cell (LSC) population significantly declined following treatment of niclosamide $\left[\mathrm{CD} 34^{+} \mathrm{CD} 38^{-}\right.$LSC in circulating leukemic cells $(\%)$, vehicle $v s$. niclosamide, after 1 week of treatment, $19.62 \pm 0.54$ vs. $15.56 \pm 54.48 ; 4$ weeks of treatment: $18.38 \pm 0.50$ vs. $10.81 \pm 0.95(n=5, p<0.01$, mean \pm SEM)] (Figure 6D).

\section{Enhanced chemotherapy sensitivity by niclosamide pretreatment}

The classical frontline treatment of AML is the "7+3" combination induction chemotherapy which consists of 7 days of cytarabine and 3 days of an anthracycline, most often daunorubicin [1]. We investigated the efficacy of niclosamide combined with chemotherapy. To assess the simultaneous treatment effects of niclosamide and chemotherapy drugs (cytarabine, daunorubicin), HL60 cells were treated with combined drugs at a fixed ratio of $\mathrm{IC}_{50}$ for niclosamide and chemotherapy drugs. The simultaneous treatment of HL60 cells with niclosamide
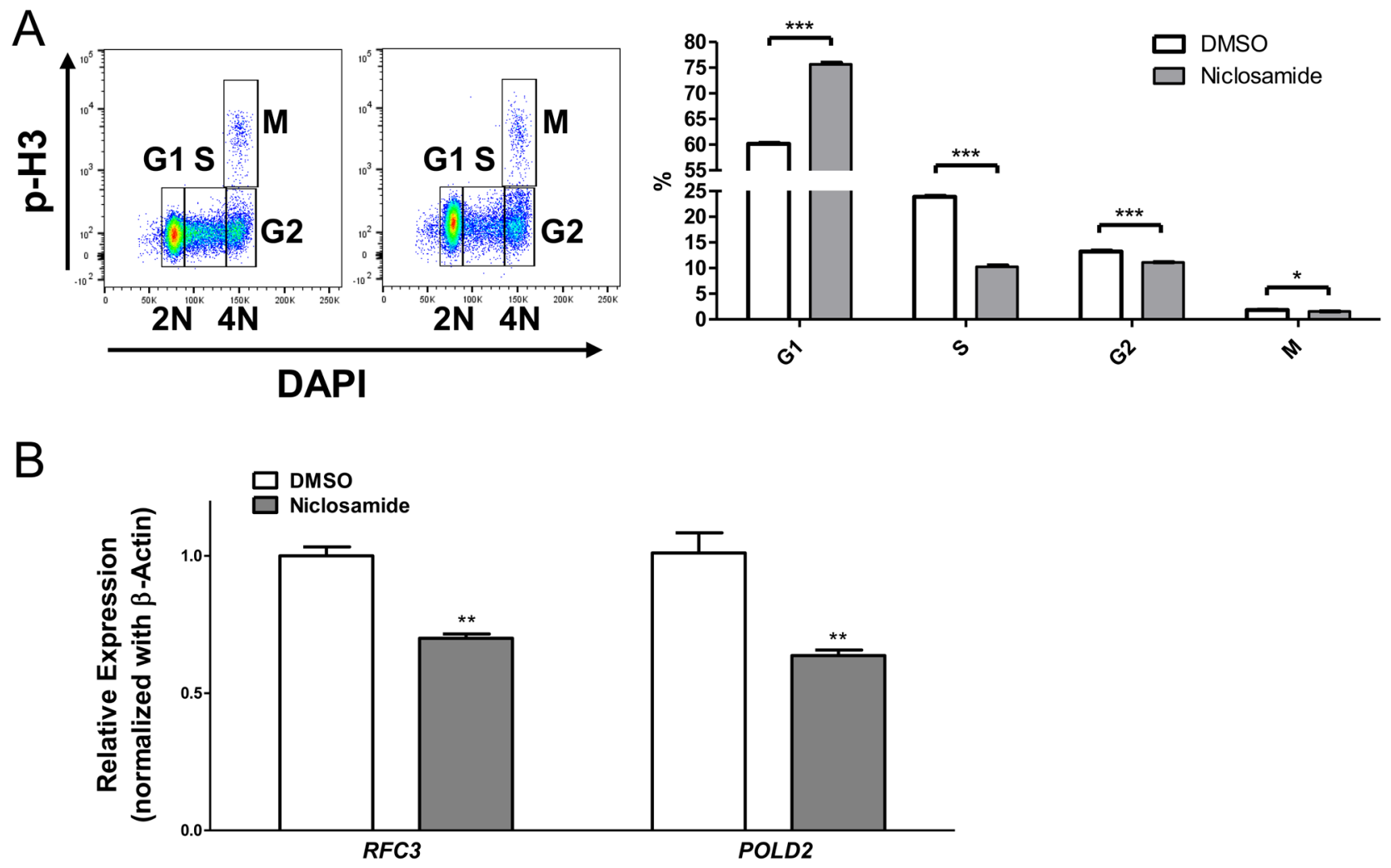

Figure 5: Niclosamide treatment induces G1/S arrest. A. HL60 cells were treated with niclosamide $(1 \mu \mathrm{M})$ for $1 \mathrm{~d}$. Cells were fixed, and then stained with anti-cPARP, anti-Cyclin A, anti-phospho-Histone H3 (p-H3) antibodies, and DAPI. c-PARP-negative live cells population was gated. $\mathrm{p}-\mathrm{H} 3$ versus DNA content displayed a typical cell cycle profile. Percentage of cells at each cell cycle phase was calculated. Values are indicated as mean $\pm \operatorname{SEM}(n=3) .{ }^{*}, p<.05 ; * * *, p<.001$. B. Downregulation of CREB-target genes $R F C 3$ and POLD2 following treatment of niclosamide $(1 \mu \mathrm{M})$ for $1 \mathrm{~d}$. RFC3 and POLD2 mRNAs were assessed by RT-qPCR and normalized against $\beta$-actin expression level. The data represent means of three independent experiments \pm SEM. $* *, p<.01$. 
and cytarabine or daunorubicin had antagonistic effects on cellular viability of HL60 cells with CI values of $>2$ (Figure 7A). Isobolograms for both combinations showed combination values to be located far upper right of the additive isoboles. We next tested a sequence-dependent combination with niclosamide and chemotherapy. Though vincristine is not used in current AML therapy, it was included in combination chemotherapy of the VAPA study, one of the first AML studies in children and adults
[39]. We examined whether chemotherapy inhibited cytotoxic potency of niclosamide. HL60 cells were treated with chemotherapy drugs (cytarabine, daunorubicin, or vincristine) and niclosamide sequentially. Several other chemotherapy drugs including decitabine, 5-azacytidine, mitoxantrone were tested for potential efficacy in combination with niclosamide (data not shown). Pretreatment of cells with chemotherapy (cytarabine, daunorubicin, or vincristine) reduced cytotoxic effects of
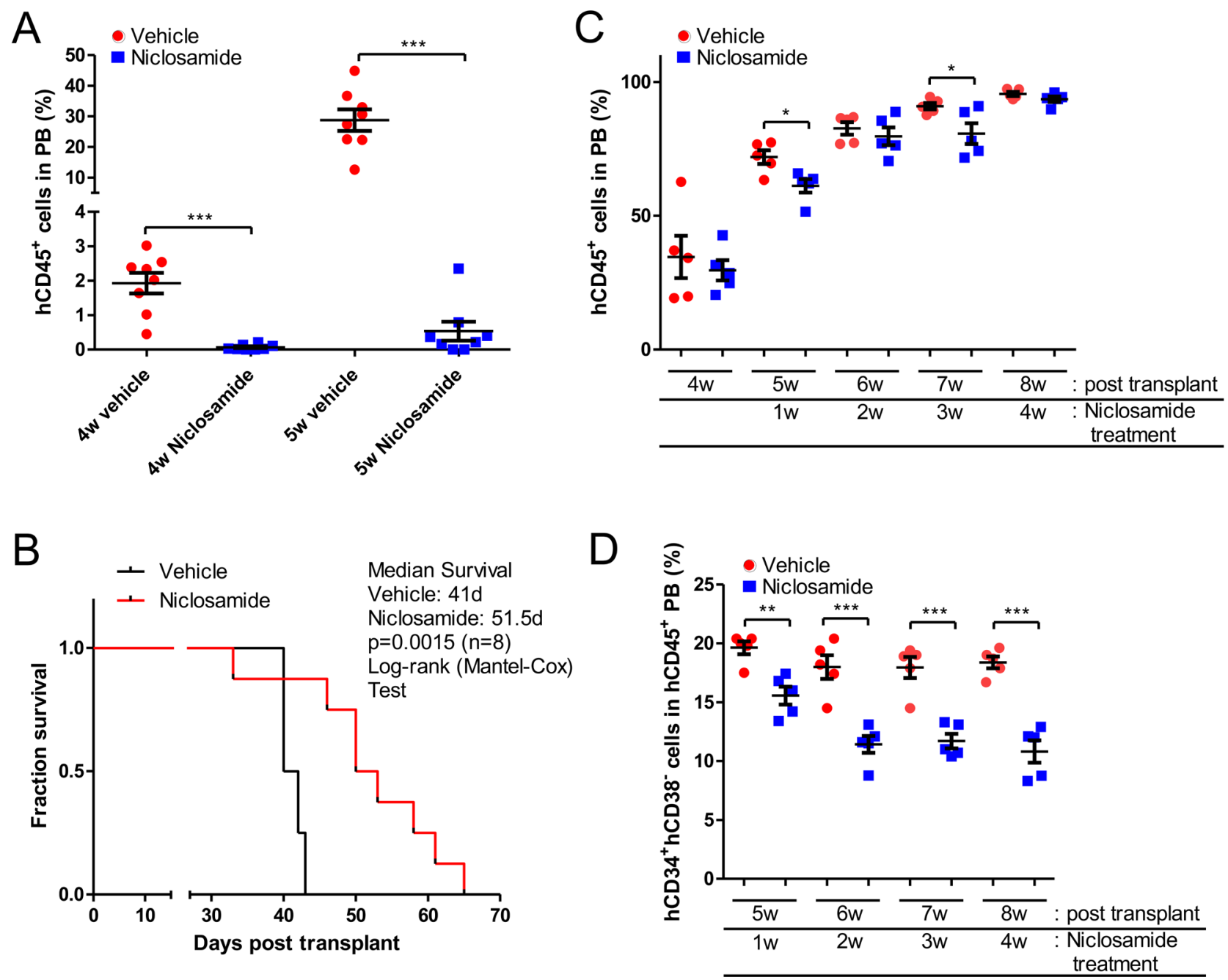

Figure 6: In vivo efficacy of Niclosamide in PDX mice. A., B. Prolonged survival of AML-PDX (186) mice. Sub-lethally irradiated NSG mice were injected with $1 \times 10^{6}$ patient AML (186) cells. Niclosamide $(200 \mathrm{mg} / \mathrm{kg})$ was given orally daily starting the day after cell injection, until death or when an endpoint was reached. Leukemia development was monitored by quantifying the fraction of human CD45positive $\left(\mathrm{hCD} 45^{+}\right)$cells in peripheral blood (PB) of AML-PDX (186) mice using flow cytometry. Niclosamide treatment results in decreased numbers of circulating AML cells (mean \pm SEM, $n=8, p>0.001$ ) (A). Survival of AML-PDX (186) mice treated with niclosamide was monitored over time, and is presented by a Kaplan-Meier plot. Median survival for niclosamide was 51.5 days compared to vehicle control of 41 days $\left(n=8, p=0.0015\right.$, log-rank test) (B). C., D. Suppression of hCD34 ${ }^{+}$hCD38- leukemia stem cell (LSC) population in AML-PDX (3123) mice by niclosamide treatment. NSG mice were injected with $1 \times 10^{6}$ patient AML cells (3123). Niclosamide $(200 \mathrm{mg} / \mathrm{kg}) \mathrm{were}$ given once daily by oral gavage starting 4 weeks after cell injection, until death or an endpoint was reached. (C) To monitor the leukemia disease progression, $\mathrm{PB}$ was analyzed to quantify the fraction of human $\mathrm{hCD} 45^{+}$cells in AML-PDX (3123) mice. Each spot represents an individual mouse. Data are graphed as mean $\pm \operatorname{SEM}(n=5)$. (D) hCD34 ${ }^{+} \mathrm{hCD} 38^{-}$LSC population of circulating human AML cells was determined by flow cytometry. Data are graphed as mean $\pm \operatorname{SEM}(n=5)$. ${ }^{*}, p<.05 ; * *, p<.001 ; * * *, p<.0001$. 
niclosamide (Figure 7B). We then investigated whether niclosamide could potentiate the activity of chemotherapy. HL60 cells were pretreated with niclosamide for 3 days prior to treatment with various doses of chemotherapeutic drugs (cytarabine, daunorubicin, or vincristine) for another
3 days. Pretreatment of cells with niclosamide followed by chemotherapeutic drugs showed a synergistic effect. The sequential combination treatment of niclosamide and chemotherapy drugs significantly lowered the viability of cells compared to chemotherapy drugs alone (Figure 8A).
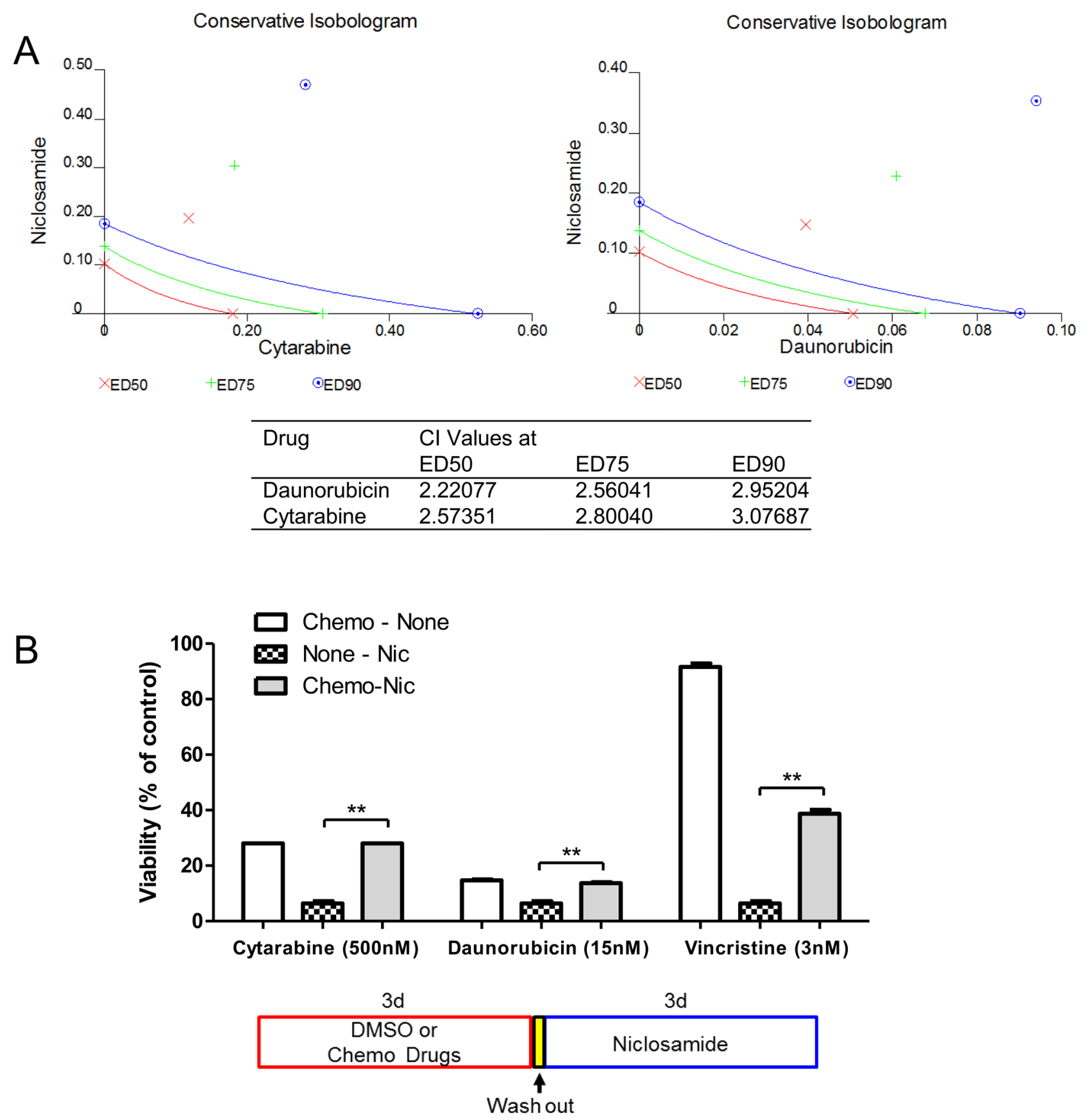

Figure 7: Inhibitory effect of chemotherapy drugs on cytotoxic response to niclosamide. A. Antagonistic effect of simultaneous treatment with niclosamide and chemotherapy drugs cytarabine and daunorubicin. Cells were treatment with different doses of niclosamide and chemotherapy drugs for $3 \mathrm{~d}$. Conservative isobolograms and CI values were generated by Chou-Talalay method using CalcuSyn software. B. Pretreatment of chemotherapy drugs resulted in resistance to niclosamide. HL60 cells were treated with cytarabine, daunorubicin, or vincristine for $3 \mathrm{~d}$, washed with culture medium twice, and then treated with niclosamide for $3 \mathrm{~d}$. Cell viability was measured using CellTiter-Glo assay. The combination of chemotherapy drugs and niclosamide was compared with niclosamide alone. A diagram shows the experimental scheme. Data are graphed as mean $\pm \operatorname{SEM}(n=3)$. ${ }^{*}, p<.001$ 

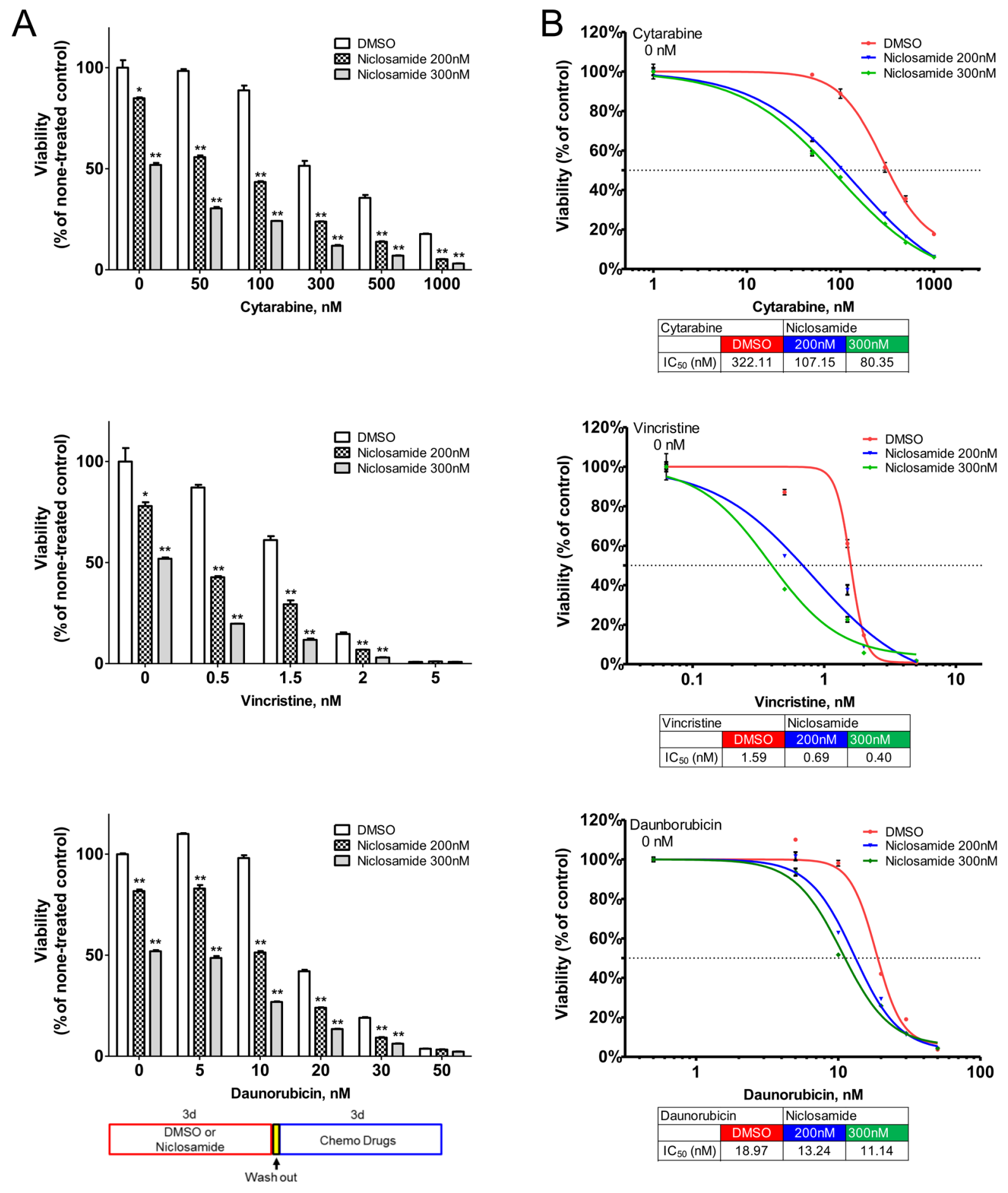

Figure 8: Synergistic cytotoxic effect of sequential treatment with niclosamide and chemotherapy drugs cytarabine, daunorubicin, and vincristine. HL60 cells were treated with niclosamide (200nM, 300nM) or DMSO for 3 days. After cells were washed with culture medium twice, cells were further incubated with various doses of chemotherapy drugs or vehicle for 3 days. A. Pretreatment of cells with niclosamide significantly potentiated the cytotoxic effects of chemotherapy drugs. Cell viability was measured using CellTiter-Glo assay and expressed as the percentage of none-treated control cells. The sequential combination of niclosamide and chemotherapy drugs was compared to the effect of chemotherapy drugs alone. The diagram shows the experimental scheme. Results are represented as mean $\pm \operatorname{SEM}(n=3){ }^{*}, p<.05 ; * *, p<.001$. B. Pretreatment with niclosamide sensitized cells to chemotherapy. The graphs show representative dose response curves. Dose response curves of chemotherapy drugs are shifted to the left with pretreatment of niclosamide. The $\mathrm{IC}_{50}$ values are indicated below the graphs. Values are presented as mean $\pm \operatorname{SEM}(n=3)$. 
Furthermore, pretreatment with niclosamide caused dosecurves of chemotherapeutic drugs to shift to the left with lower $\mathrm{IC}_{50 \mathrm{~s}}$, suggesting that pretreatment with niclosamide conferred sensitivity to these chemotherapeutic agents even at suboptimal doses (Figure 8B).

\section{DISCUSSION}

We previously demonstrated that CREB overexpression increases leukemia cell growth and survival [6, 13], and inhibition of CREB by a small molecule, XX-650-23, or shRNA induces cell cycle arrest and apoptosis in AML cells [14, 17, 36]. The tool compound XX-650-23 inhibits CREB transcriptional activity, leading to suppression of viability of AML cells in vitro and prolonged survival of AML xenograft mice with no toxicity [17]. However, the potency, solubility, and half-life of XX-650-23 are not adequate for clinical application. In this study, we demonstrated that niclosamide, a well-tolerated FDA-approved oral anthelminthic drug, selectively blocked CREB activation, disrupted CREB-CBP interaction, and inhibited CREBdriven genes expression, resulting in inhibition of AML cell viability in vitro and leukemia progression in AMLPDX mice.

In recent studies, niclosamide has been identified as a potent anticancer drug in a broad range of tumor cells [20, 23-25]. In addition, niclosamide inhibits cell proliferation of NCI-60 human tumor cell lines with $\mathrm{IC}_{50}$ of less than $1 \mu \mathrm{M}$ [23]. Though niclosamide has been reported to target several signaling pathways including Wnt/ $\beta$-catenin, mTORC1, STAT3, NF- $\kappa$ B and Notch [20, 23-25, 34, 40], the mechanism of action of niclosamide in AML has not been extensively studied.

A previous report described inhibition of tumor necrosis factor (TNF)-induced $\mathrm{NF}-\kappa \mathrm{B}$ activation as a potential mechanism of niclosamide action in AML cells [25]. However, without TNF stimulation, NF- $\kappa \mathrm{B}$ activation was not observed in our results and niclosamide did not show any further inhibition of NF- $\kappa \mathrm{B}$. Phosphorylation at

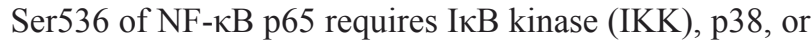
ribosomal S6 kinase 1 (RSK1) [41], but niclosamide has not been reported to inhibit 95 kinases including NF- $\kappa \mathrm{B}$ p65 kinase up to $10 \mu \mathrm{M}$ in in vitro kinase assays [40]. Recently, Tang et al. showed that niclosamide derivatives did not show the correlation between anti-proliferative effects with inhibition of $\mathrm{NF}-\kappa \mathrm{B}$ or mitochondrial transmembrane potential in HL60 cells [42]. We did not observe the reduction of p- NF- $\kappa \mathrm{B}$ p65 (S536)-positive population in HL60 and KG1 cells following treatment of niclosamide (Figure 4B), consistent with the previous in vitro IKK assay [40]. STAT3 was inhibited only in KG1 cells, but not in HL60 cells, following treatment of niclosamide. Based on our data and recent reports, CREB appears to be a potential target of niclosamide in AML cells.
While the oral bioavailability of niclosamide was only $10 \%$ in rats due to its poor solubility and absorption [43], niclosamide is well-tolerated in mammals (1000 or $2500 \mathrm{mg} / \mathrm{kg}$ b.w. oral daily for 55 or 64 days, thereafter 10,000 and $25,000 \mathrm{mg} / \mathrm{kg}$ feed; total duration $365-381$ days in male rats without any damage based on clinical symptoms, hematolology/clinical chemistry tests, and histopathological examination) [18]. Our data first demonstrated that oral administration of niclosamide significantly inhibited AML progression in PDX mice (Figure 6). A single $2 \mathrm{~g}$ oral dose of niclosamide to adults for cestocidal treatment or a single $5 \mathrm{mg} / \mathrm{kg}$ oral dose to rats leads to maximum plasma concentrations of $0.76-18.35 \mu \mathrm{M}$ [18] and $1.08 \mu \mathrm{M}$ [43], respectively. These plasma concentrations should be sufficient to suppress AML cell viability in humans or increase sensitivity of AML cells to chemotherapy. Niclosamide is cleared rapidly from plasma. Plasma concentration decrease to $0.11 \mu \mathrm{M}$, below active dose, 2 hours after oral administration in rats [43]. Since there is a high tolerability of repeated high doses of niclosamide, clinical active plasma concentration of niclosamide can be maintained safely.

Schedule-dependent synergy was observed when we tested the effects of niclosamide and chemotherapy drugs, cytarabine, daunorubicin, or vincristine. Chemotherapyinduced DNA damage activates the cell cycle checkpoints to stop cell cycle progression for DNA repair by activating DNA damage response (DDR) signaling pathways, ATM/ ATR-CHK1/CHK2-p53 axis [44]. We postulate that activate DDR pathways turn on the DNA repair and survival proteins, which could increase the threshold to trigger cell death by niclosamide treatment. Niclosamide reduced expression of $R F C 3$ and POLD2, which support this hypothesis. RFC3 is required for DNA replication, DNA repair, and DDR checkpoint control [45]. RFC complexes function to load clamp proteins, proliferating cell nuclear antigen (PCNA) or checkpoint 9-1-1 complex (Rad9-Rad1-Hus1) on chromatin [46]. PCNA provides a platform for DNA metabolism-related proteins to process DNA replication, DNA repair, and cell cycle control [4750]. Rad17-RFC loads the 9-1-1 complex to activate ATR, which turns on DDR signaling and cell cycle checkpoints $[46,51]$. CREB regulates RFC3 expression to control G1/S progression by modulating chromatin loading of PCNA in AML cells [36]. DNA polymerase delta is also an essential component for DNA replication and DNA repair [52]. Downregulation of these CREB-driven genes could diminish the capacity of DDR and DNA repair, which lowers threshold to turn on cell death pathway following chemotherapy. Taken together, our study provides preclinical evidence that supports a possible strategy of incorporating niclosamide as a single agent or in combination with chemotherapy to treat AML patients. Furthermore, lowering the dose of chemotherapy used in combination with niclosamide could prevent some of the 
known toxicities and long-term complications observed with AML therapy. This is particularly relevant for AML patients in third world countries where supportive care is severely limited. Therefore, our study provides a potentially novel approach to treat AML patients and needs further investigation in clinical trials.

\section{MATERIALS AND METHODS}

\section{Cell culture}

Human acute myeloid leukemia cells were cultured at $37^{\circ} \mathrm{C}$ with $5 \% \mathrm{CO}_{2}$ in following medium; IMDM $/ 10 \%$ fetal bovine serum (FBS)/1\% penicillin/streptomycin/ glutamine (PSG) for HL60, KG1, and MV4-11 cells, RPMI1640/20\% FBS/1\% PSG for MOLM13 cells, RPMI1640/10\%FBS/1\% PSG for U937 cells. Cell lines were obtained from ATCC (Manassus, VA, USA) and low-passage stocks were used and cultured for less than 3 months maintained. Cells were regularly tested for Mycoplasma and growth characteristics. Primary AML cells were cultured in IMDM/15\% BIT (bovine serum albumin, insulin, transferrin; Stem Cell Technologies, Vancouver, BC, Canada)/SCF (100 ng/ml, Miltenyi Biotec, Auburn, CA, USA)/FLT3-ligand (50 ng/ml, Miltenyi Biotec)/IL3 (20 ng/ml, Miltenyi Biotec)/IL6 (20 ng/ml, Miltenyi Biotec)/TPO (50 ng/ml, Miltenyi Biotec)/ GMCSF (20 ng/ml, R\&D Systems, Minneapolis, MN, USA) $/ 55 \mu \mathrm{M} \beta$-mercaptoethanol/0.75 $\mu \mathrm{M}$ SR1 (Selleck Chemicals, Houston, TX, USA)/35 nM UM171 (Stem Cell Technologies), as described previously [53, 54]. Bone marrow from AML patients were collected through voluntary patient participation at Stanford University (Palo Alto, California, USA) in compliance with the Institutional Review Board regulations. Informed consent was obtained from all human subjects in accordance with the declaration of Helsinki and the Data Protection Directive. HL60 cells were transduced with lentivirus expressing CREB shRNAs [14] to generate CREB knockdown cells. Lentivirus-infected cells were isolated using a FACS Aria (BD Biosciences, San Jose, CA, USA) $3 \mathrm{~d}$ after transduction.

\section{Cell viability and apoptosis analysis}

For cell viability assays, AML cell lines and primary AML cells were seeded at $2 \times 10^{4}$ cells/well in 96-well plates, and then treated with niclosamide for 3 or 4 days, respectively. CellTiter-Glo assays (Promega, Madison, WI, USA) were performed to assess viability of cells. The software program GraphPad Prism version 5.0 (GraphPad Software, La Jolla, CA) was used to determine the concentration inhibiting cell viability by $50 \%$ (IC50). For combination experiments, combination index values were calculated by Chou-Talalay method using CalcuSyn software (Biosoft, Ferguson, MO, USA) as described [55]. CI values were used to determine synergism $(\mathrm{CI}<1)$, antagonism $(\mathrm{CI}>1)$ and additivity $(\mathrm{CI}=1)$. Cells were treated with combined drugs at a constant ratio of IC50 for two drugs. Additivity ranges of CI scores were also determined from sham mixtures.

Apoptosis was measured by Annexin-V (Biolegend, San Diego, CA, USA) / 4',6-diamidino-2-phenylindole (DAPI) double staining according to manufacturer's instructions. Stained cells were analyzed on a DxP10 FACScan (BD Biosciences/Cytek Development, Fremont, CA, USA).

\section{Hematopoietic cell colony assays}

Normal human bone marrow cells or primary AML cells were plated in methylcellulose $\left(2 \times 10^{4}\right.$ cells/ $\mathrm{mL}$, Miltenyi Biotec) containing cytokines (GM-CSF, G-CSF, IL-3, IL-6, SCF, erythropoietin) to assess colonyforming cell units. Colonies were scored on the basis of morphology after 2 weeks of culture.

\section{RNA extraction and quantitative reverse transcription PCR (qRT- PCR)}

mRNA expression was assessed by quantitative reverse transcription PCR as described previously [17, 36]. Total RNA was extracted from cells using QIAGEN RNAeasy Mini Kit (Qiagen, Valencia, CA, USA) according to the manufacturer's instructions and used for cDNA synthesis by iScript cDNA Synthesis Kit (BioRad, Hercules, CA, USA). PCR was carried out on a CFX384 Real-time PCR system (BioRad) using IQ ${ }^{\mathrm{TM}}$ SYBR® Green Supermix (BioRad). The $\beta$-actin was used as a control gene. Relative expression levels were calculated as $2^{-\Delta \Delta \mathrm{CT}}[56]$.

\section{CREB-dependent transcription and KIX-KID interaction assays}

To determine the inhibitory effect of niclosamide on CREB-dependent transcription, HL60 cells expressing a Firefly luciferase under CREB-driven promoter was generated, as previously described [17, 37]. Cells were seeded at $7.5 \times 10^{4}$ cells/well in 96-well plates, and then cultured with various concentrations of niclosamide for 6h. Bright Glo assay system (Promega) was used to measure Firefly luciferase activity. KIXKID interaction was monitored using the split Renilla luciferase complementation assay [57]. HEK 293 cells were transfected with vectors expressing KID domain fused to N-terminal Renilla luciferase and KIX domains fused to C- terminal Renilla luciferase using TransIT-293 
transfection reagent (Mirus Bio, Madison, WI, USA). Next day, transfected cells were replated in 96-well plates. Cells were allowed to attach overnight, then treated with different doses of compounds $0.5 \mathrm{~h}$ before stimulation with forskoin $(6 \mu \mathrm{M})$. Cells were further cultured for 1.5h. Subsequently, culture media was discarded, and then $100 \mu$ l of phosphate-buffered saline (PBS) containing coeletarazine $(20 \mu \mathrm{M})$ was added to determine Renilla luciferase activity.

\section{Flow cytometry analysis}

For detection of intracellular proteins by flow cytometry, cells were fixed with $1.6 \%$ paraformaldehyde for $10 \mathrm{~min}$, and then post-fixed in cold-methanol at $-70^{\circ} \mathrm{C}$. Fixed cells were washed and incubated with antibodies and DAPI (0.1ug/ml, Sigma, St. Louis, MO, USA) in PBS with $1 \%$ BSA. The following antibodies were used in intracellular protein staining: PE-conjugated anti-Cyclin A (clone BF683), Alexa Fluor 647-conjugated anti-cPARP (clone F21-852), PE-conjugated anti-pCERB (pS133) (clone J151-21), Alexa Fluor 488-conjugated anti-pSTAT1 (pY701) (clone 4a), PE-conjugated anti-pSTAT3 (pY705) (clone 4/P-STAT3), Alexa Fluor 647-conjugated antipSTAT5 (pY694) (clone 47, BD Biosciences); PECy7conjugated ant-pH3 (pS28) (clone HTA283, Biolegend); Alex Fluor 647-conjugated anti-p-NFkB p65 (pS536) (clone 93H1, Cell Signaling Technology, Danvers, MA, USA).

To assess engrafted cell populations with cell surface markers, cells were stained with FITC-conjugated antihCD34 (AC136, Miltenyi Biotec), PE-conjugated antihCD38 (HB7, BD Biosciences), and APC-conjugated antihCD45 (HI30, Biolegend) antibodies. DAPI was included in staining solutions to remove dead cell population. Cells were analyzed on FACSCalibur (BD Biosciences) or DxP10 FACScan (BD Biosciences/Cytek Development).

\section{AML PDX mice}

All mouse experiments were subject to institutional approval by Stanford University Institutional Animal Care and Use Committee. For AML PDX mice experiments, patient primary AML cells $\left(1 \times 10^{6}\right.$ per mouse $)$ were injected in to sub-lethally irradiated NOD.Cg-Prkdc $c^{\text {scid }}$ $I l 2 \mathrm{rg}^{t m l \mathrm{Wjl}^{\prime}} / \mathrm{SzJ}$ (NSG) mice (primary xenograft mice) for engraftment. Patient AML cells from primary xenograft mice were injected into secondary xenograft mice to expand patient AML cells. Cells from secondary xenograft mice were injected into sub-lethally irradiated NSG mice for in vivo efficacy test of niclosamide. Engrafted mice were randomly divided into two groups. Mice were separated into two groups of $200 \mathrm{mg} / \mathrm{kg}$ niclosamide (formulated in $0.5 \% \mathrm{w} / \mathrm{v}$ methylcellulose $/ 0.1 \% \mathrm{v} / \mathrm{v}$ Tween 80) treatment and vehicle. The treatment was given once daily by oral gavage starting 24 hours after cell infection or 4 weeks after cell injection. Leukemia disease progression in mice was monitored by flow cytometry analysis of circulating leukemic cells in PB. After lysing red blood cells, cells were stained with anti-hCD45, hCD34, hCD38 antibodies. Percentage of each population was measured on a flow cytometer. The overall survival of mice was monitored to determine the median survival.

\section{Statistical analysis}

Unless otherwise stated, all experiments were performed in triplicate, and statistical significance was determined using the unpaired two-tailed Student's t-test. Kaplan-Meier plots and statistical significance of differences in mice survival experiments were calculated using a Log-rank (Mantel-Cox) test with Prism. Isobologram analysis for combination treatment analysis was performed using the CalcuSyn software program.

\section{Author contributions}

Hee-Don Chae: designed and performed experiments, analyzed data and wrote the manuscript.

Nick Cox: identified niclosamide through structure activity relationship studies, performed experiments and critically read and edited the manuscript.

Gary Dahl: provided patient samples, and critically read and edited the manuscript.

Norman J. Lacayo: provided patient samples, and critically read and edited the manuscript.

Kara Davis: provided patient samples, and critically read and edited the manuscript.

Samanta Cappolicchio: assisted with SAR studies and critically read and edited the manuscript.

Mark Smith: designed experiments and critically read and edited the manuscript.

Kathleen M. Sakamoto: designed experiments and critically read and edited the manuscript.

\section{ACKNOWLEDGMENTS}

We would like to acknowledge Vivian Zhang for technical assistance.

\section{CONFLICTS OF INTEREST}

The authors have no conflicts of interest to declare.

\section{FUNDING}

This research was supported by SPARK Pilot Grant Program, Pediatric Cancer Research Foundation, Bear Necessities Foundation, Leukemia and Lymphoma 
Society Screen to Lead Program, USC Parker Institute for Childhood Cancer Research/William Lawrence \& Blanche Hughes Foundation (K.M.S.). Sorting was performed on an instrument in the Shared FACS Facility obtained using NIH S10 Shared Instrument Grant S10RR025518-01.

\section{REFERENCES}

1. Kavanagh S, Murphy T, Law A, Yehudai D, Ho JM, Chan $\mathrm{S}$, Schimmer AD. Emerging therapies for acute myeloid leukemia: translating biology into the clinic. JCI Insight. 2017; 2. doi: 10.1172/jci.insight.95679.

2. Dohner H, Weisdorf DJ, Bloomfield CD. Acute Myeloid Leukemia. N Engl J Med. 2015; 373: 1136-52. doi: 10.1056/NEJMra1406184.

3. Saygin C, Carraway HE. Emerging therapies for acute myeloid leukemia. J Hematol Oncol. 2017; 10: 93. doi: 10.1186/s13045-017-0463-6.

4. Frohling S, Scholl C, Gilliland DG, Levine RL. Genetics of myeloid malignancies: pathogenetic and clinical implications. J Clin Oncol. 2005; 23: 6285-95. doi: 10.1200/ JCO.2005.05.010.

5. Fialkow PJ, Janssen JW, Bartram CR. Clonal remissions in acute nonlymphocytic leukemia: evidence for a multistep pathogenesis of the malignancy. Blood. 1991; 77: 1415-7.

6. Crans-Vargas HN, Landaw EM, Bhatia S, Sandusky G, Moore TB, Sakamoto KM. Expression of cyclic adenosine monophosphate response-element binding protein in acute leukemia. Blood. 2002; 99: 2617-9.

7. Mayr B, Montminy M. Transcriptional regulation by the phosphorylation-dependent factor CREB. Nat Rev Mol Cell Biol. 2001; 2: 599-609. doi: 10.1038/35085068.

8. Siu YT, Jin DY. CREB - a real culprit in oncogenesis. FEBS J. 2007; 274: 3224-32. doi: 10.1111/j.17424658.2007.05884.x.

9. Radhakrishnan I, Perez-Alvarado GC, Parker D, Dyson HJ, Montminy MR, Wright PE. Solution structure of the KIX domain of CBP bound to the transactivation domain of CREB: a model for activator:coactivator interactions. Cell. 1997; 91: 741-52.

10. Chrivia JC, Kwok RP, Lamb N, Hagiwara M, Montminy MR, Goodman RH. Phosphorylated CREB binds specifically to the nuclear protein CBP. Nature. 1993; 365 : 855-9. doi: 10.1038/365855a0.

11. Kwok RP, Lundblad JR, Chrivia JC, Richards JP, Bachinger HP, Brennan RG, Roberts SG, Green MR, Goodman RH. Nuclear protein CBP is a coactivator for the transcription factor CREB. Nature. 1994; 370: 223-6. doi: 10.1038/370223a0

12. Haus-Seuffert P, Meisterernst M. Mechanisms of transcriptional activation of cAMP-responsive elementbinding protein CREB. Mol Cell Biochem. 2000; 212: 5-9.

13. Shankar DB, Cheng JC, Kinjo K, Federman N, Moore TB, Gill A, Rao NP, Landaw EM, Sakamoto KM. The role of
CREB as a proto-oncogene in hematopoiesis and in acute myeloid leukemia. Cancer cell. 2005; 7: 351-62. doi: 10.1016/j.ccr.2005.02.018.

14. Cheng JC, Kinjo K, Judelson DR, Chang J, Wu WS, Schmid I, Shankar DB, Kasahara N, Stripecke R, Bhatia R, Landaw EM, Sakamoto KM. CREB is a critical regulator of normal hematopoiesis and leukemogenesis. Blood. 2008; 111: 1182-92. doi: 10.1182/blood-2007-04-083600.

15. Stein EM, Tallman MS. Emerging therapeutic drugs for AML. Blood. 2016; 127: 71-8. doi: 10.1182/ blood-2015-07-604538.

16. Siveen KS, Uddin S, Mohammad RM. Targeting acute myeloid leukemia stem cell signaling by natural products. Mol Cancer. 2017; 16: 13. doi: 10.1186/s12943-0160571-x.

17. Mitton B, Chae HD, Hsu K, Dutta R, Aldana-Masangkay G, Ferrari R, Davis K, Tiu BC, Kaul A, Lacayo N, Dahl G, Xie F, Li BX, et al. Small molecule inhibition of cAMP response element binding protein in human acute myeloid leukemia cells. Leukemia. 2016; 30: 2302-11. doi: 10.1038/ leu.2016.139.

18. Andrews P, Thyssen J, Lorke D. The biology and toxicology of molluscicides, Bayluscide. Pharmacol Ther. 1982; 19: 245-95.

19. Pearson RD, Hewlett EL. Niclosamide therapy for tapeworm infections. Ann Intern Med. 1985; 102: 550-1.

20. Chen W, Mook RA Jr, Premont RT, Wang J. Niclosamide: Beyond an antihelminthic drug. Cell Signal. 2017; 41:8996. doi: 10.1016/j.cellsig.2017.04.001.

21. WHO. (2002). WHO Specifications and Evaluations for Public Health Pesticides: Niclosamide. World Health Organisation, Geneva. Available from: http://www.who. int/whopes/quality/en/Niclosamide.pdf.

22. Al-Hadiya BM. Niclosamide: comprehensive profile. Profiles Drug Subst Excip Relat Methodol. 2005; 32: 6796. doi: 10.1016/S0099-5428(05)32002-8.

23. Li Y, Li PK, Roberts MJ, Arend RC, Samant RS, Buchsbaum DJ. Multi-targeted therapy of cancer by niclosamide: A new application for an old drug. Cancer Lett. 2014; 349: 8-14. doi: 10.1016/j.canlet.2014.04.003.

24. Moskaleva EY, Perevozchikova VG, Zhirnik AS, Severin SE. [Molecular mechanisms of niclosamide antitumor activity]. [Article in Russian]. Biomed Khim. 2015; 61: 680-93. doi: 10.18097/PBMC20156106680.

25. Jin Y, Lu Z, Ding K, Li J, Du X, Chen C, Sun X, Wu Y, Zhou J, Pan J. Antineoplastic mechanisms of niclosamide in acute myelogenous leukemia stem cells: inactivation of the NF-kappaB pathway and generation of reactive oxygen species. Cancer Res. 2010; 70: 2516-27. doi: 10.1158/00085472.CAN-09-3950.

26. Bolton EE, Kim S, Bryant SH. PubChem3D: Similar conformers. J Cheminform. 2011; 3: 13. doi: 10.1186/17582946-3-13.

27. Yan X, Liao C, Liu Z, Hagler AT, Gu Q, Xu J. Chemical 
Structure Similarity Search for Ligand-based Virtual Screening: Methods and Computational Resources. Curr Drug Targets. 2016; 17: 1580-5.

28. Willett P, Barnard JM, Downs GM. Chemical Similarity Searching. Journal of Chemical Information and Computer Sciences. 1998; 38: 983-96. doi: 10.1021/ci9800211.

29. Burgess DJ, Doles J, Zender L, Xue W, Ma B, McCombie WR, Hannon GJ, Lowe SW, Hemann MT. Topoisomerase levels determine chemotherapy response in vitro and in vivo. Proc Natl Acad Sci U S A. 2008; 105: 9053-8. doi: 10.1073/pnas.0803513105.

30. Jiang H, Pritchard JR, Williams RT, Lauffenburger DA, Hemann MT. A mammalian functional-genetic approach to characterizing cancer therapeutics. Nat Chem Biol. 2011; 7: 92-100. doi: 10.1038/nchembio.503.

31. Jia J, Zhu F, Ma X, Cao Z, Li Y, Chen YZ. Mechanisms of drug combinations: interaction and network perspectives. Nat Rev Drug Discov. 2009; 8: 111-28. doi: 10.1038/ $\operatorname{nrd} 2683$.

32. Breitinger HG. (2012). Drug Synergy - Mechanisms and Methods of Analysis, Toxicity and Drug Testing. In: Acree $\mathrm{PB}$, ed. InTech.

33. Lazebnik YA, Kaufmann SH, Desnoyers S, Poirier GG, Earnshaw WC. Cleavage of poly(ADP-ribose) polymerase by a proteinase with properties like ICE. Nature. 1994; 371: 346-7. doi: 10.1038/371346a0.

34. Ren X, Duan L, He Q, Zhang Z, Zhou Y, Wu D, Pan J, Pei D, Ding K. Identification of Niclosamide as a New SmallMolecule Inhibitor of the STAT3 Signaling Pathway. ACS Med Chem Lett. 2010; 1: 454-9. doi: 10.1021/ml100146z.

35. Nicolas E, Golemis EA, Arora S. POLD1: Central mediator of DNA replication and repair, and implication in cancer and other pathologies. Gene. 2016; 590: 128-41. doi: 10.1016/j.gene.2016.06.031.

36. Chae HD, Mitton B, Lacayo NJ, Sakamoto KM. Replication factor $\mathrm{C} 3$ is a CREB target gene that regulates cell cycle progression through the modulation of chromatin loading of PCNA. Leukemia. 2015; 29: 1379-89. doi: 10.1038/ leu.2014.350.

37. Mitton B, Hsu K, Dutta R, Tiu BC, Cox N, McLure KG, Chae HD, Smith M, Eklund EA, Solow-Cordero DE, Sakamoto KM. Small molecule screen for inhibitors of expression from canonical CREB response elementcontaining promoters. Oncotarget. 2016; 7: 8653-62. doi: 10.18632/oncotarget.7085.

38. Lai Y, Wei X, Lin S, Qin L, Cheng L, Li P. Current status and perspectives of patient-derived xenograft models in cancer research. J Hematol Oncol. 2017; 10: 106. doi: 10.1186/s13045-017-0470-7.

39. Weinstein HJ, Mayer RJ, Rosenthal DS, Coral FS, Camitta BM, Gelber RD. Chemotherapy for acute myelogenous leukemia in children and adults: VAPA update. Blood. 1983; 62: 315-9.

40. Fonseca BD, Diering GH, Bidinosti MA, Dalal K, Alain
T, Balgi AD, Forestieri R, Nodwell M, Rajadurai CV, Gunaratnam C, Tee AR, Duong F, Andersen RJ, et al. Structure-activity analysis of niclosamide reveals potential role for cytoplasmic $\mathrm{pH}$ in control of mammalian target of rapamycin complex 1 (mTORC1) signaling. J Biol Chem. 2012; 287: 17530-45. doi: 10.1074/jbc.M112.359638.

41. Viatour P, Merville MP, Bours V, Chariot A. Phosphorylation of NF-kappaB and IkappaB proteins: implications in cancer and inflammation. Trends Biochem Sci. 2005; 30: 43-52. doi: 10.1016/j.tibs.2004.11.009.

42. Tang ZH, Acuna UM, Fernandes NF, Chettiar S, Li PK, De Blanco EC. Structure-Activity Relationship of Niclosamide Derivatives. Anticancer Research. 2017; 37: 2839-43.

43. Chang YW, Yeh TK, Lin KT, Chen WC, Yao HT, Lan SJ, Wu YS, Hsieh HP, Chen CM, Chen CT. Pharmacokinetics of anti-SARS-CoV agent niclosamide and its analogs in rats. Journal of Food and Drug Analysis. 2006; 14: 329-33.

44. Roos WP, Thomas AD, Kaina B. DNA damage and the balance between survival and death in cancer biology. Nat Rev Cancer. 2016; 16: 20-33. doi: 10.1038/nrc.2015.2.

45. Shimada M, Okuzaki D, Tanaka S, Tougan T, Tamai KK, Shimoda C, Nojima H. Replication factor C3 of Schizosaccharomyces pombe, a small subunit of replication factor C complex, plays a role in both replication and damage checkpoints. Mol Biol Cell. 1999; 10: 3991-4003.

46. Sancar A, Lindsey-Boltz LA, Unsal-Kacmaz K, Linn S. Molecular mechanisms of mammalian DNA repair and the DNA damage checkpoints. Annu Rev Biochem. 2004; 73: 39-85. doi: 10.1146/annurev.biochem.73.011303.073723.

47. Stoimenov I, Helleday T. PCNA on the crossroad of cancer. Biochem Soc Trans. 2009; 37: 605-13. doi: 10.1042/ BST0370605.

48. Prosperi E. The fellowship of the rings: distinct pools of proliferating cell nuclear antigen trimer at work. FASEB J. 2006; 20: 833-7. doi: 10.1096/fj.05-5469hyp.

49. Moldovan GL, Pfander B, Jentsch S. PCNA, the maestro of the replication fork. Cell. 2007; 129: 665-79. doi: 10.1016/j. cell.2007.05.003.

50. Maga G, Hubscher U. Proliferating cell nuclear antigen (PCNA): a dancer with many partners. J Cell Sci. 2003; 116: 3051-60. doi: 10.1242/jcs.00653.

51. Parrilla-Castellar ER, Arlander SJ, Karnitz L. Dial 9-1-1 for DNA damage: the Rad9-Hus1-Rad1 (9-1-1) clamp complex. DNA Repair (Amst). 2004; 3: 1009-14. doi: 10.1016/j.dnarep.2004.03.032.

52. Lu X, Tan CK, Zhou JQ, You M, Carastro LM, Downey $\mathrm{KM}$, So AG. Direct interaction of proliferating cell nuclear antigen with the small subunit of DNA polymerase delta. J Biol Chem. 2002; 277: 24340-5. doi: 10.1074/jbc. M200065200.

53. Fares I, Chagraoui J, Gareau Y, Gingras S, Ruel R, Mayotte N, Csaszar E, Knapp DJ, Miller P, Ngom M, Imren S, Roy DC, Watts KL, et al. Cord blood expansion. Pyrimidoindole derivatives are agonists of human hematopoietic stem cell 
self-renewal. Science. 2014; 345: 1509-12. doi: 10.1126/ science. 1256337.

54. Pabst C, Krosl J, Fares I, Boucher G, Ruel R, Marinier A, Lemieux S, Hebert J, Sauvageau G. Identification of small molecules that support human leukemia stem cell activity ex vivo. Nat Methods. 2014; 11: 436-42. doi: 10.1038/ nmeth.2847.

55. Bijnsdorp IV, Giovannetti E, Peters GJ. Analysis of drug interactions. Methods Mol Biol. 2011; 731: 421-34. doi: 10.1007/978-1-61779-080-5_34.
56. Livak KJ, Schmittgen TD. Analysis of relative gene expression data using real-time quantitative PCR and the 2(-Delta Delta C(T)) Method. Methods. 2001; 25: 402-8. doi: 10.1006/meth.2001.1262.

57. Li BX, Xiao X. Discovery of a small-molecule inhibitor of the KIX-KID interaction. Chembiochem. 2009; 10: 2721-4. doi: 10.1002/cbic.200900552. 